\title{
Measurement of digital video broadcasting-second generation terestrial (DVB-T2) signal in Kuala Lumpur, Malaysia
}

\author{
Norsuzila Ya'acob ${ }^{1}$, Noraisyah Tajudin ${ }^{2}$, Mashira Meri @ Mohamad Zamiri ${ }^{3}$, Azita Laily Yusof ${ }^{4}$, \\ Suzi Seroja Sarnin ${ }^{5}$, Azlina Idris ${ }^{6}$ \\ 1,2,3,4,5,6 Faculty of Electrical Engineering, Universiti Teknologi MARA, 404500 Shah Alam Selangor, Malaysia \\ 1,2,4,5,6 Wireless Communication Technology (WiCoT), Faculty of Electrical Engineering, UniversitiTeknologi MARA, \\ 404500 Shah Alam Selangor, Malaysia
}

\section{Article Info}

Article history:

Received Sep 9, 2018

Revised Dec 12, 2018

Accepted Dec 28, 2018

\section{Keywords:}

BER

DTT

DVB-T2

Field Strength

MER

\begin{abstract}
DVB-T2 (Digital Video Broadcasting-Second Generation Terrestrial) is one of the latest technical standards being developed by the DVB Project for DTT (Digital Terrestrial Television). It is also known as digital broadcasting trough terrestrial system since 2006 and is an extension of the DVB-T system as a second generation program to improve efficiency of the total system. It is important to perform a research on the performance of DVB-T2 because Malaysia has launched the free-to-air digital TV project since 2016 hence there is a need to know how well the signal is being received by viewers. This research focuses on a DVB-T2 transmission process which involve the transmission from Menara Kuala Lumpur transmitter to receivers located at 100 different locations. The performance of DVB-T2 can be determined by measuring the field strength, MER (Module Error Ratio) and BERaLDPC (Bit Error Rate after Low Density Parity Check decoder), and then a comparison between DVB-T and DVB-T2 systems can be made. Equipments involved in the measurement are indoor antenna, distribution amplifier, waveform monitor, field strength meter, DVB-T2 decoder and TV set as the receiver. Results are recorded in Microsoft Excel and analyzed using MATLAB software. The result of the measurement shows $92 \%$ of the test points had higher reading than the baseline value which means better reception of digital TV signal is delivered to the location.Comparison between DVB-T and DVB-T2 performance shows that field strength of the DVB-T2 system is slightly higher by $1.5 \%-3.8 \%$ from DVB-T.
\end{abstract}

Copyright @ 2018Institute of Advanced Engineering and Science. All rights reserved.

\section{Corresponding Author:}

Norsuzila Ya'acob,

Faculty of Electrical Engineering, Universiti Teknologi MARA, 404500 Shah Alam Selangor, Malaysia.

Email: norsuzila@salam.uitm.edu.my

\section{INTRODUCTION}

In Malaysia, there are two main forms of television broadcasting which are analog and digital forms. Radio Television Malaysia (RTM) was the first agency to launch analog broadcasting starting from 28 December 1963. On 10 April 2011, RTM took a big leap into a launching trial version of digital television broadcasting using the DVB-T system. Accordingly, RTM (Radio Televisyen Malaysia)has been running a pilot project in September 2006 using astandard DVB-T adopted in most European countries. There are several standards currently used worldwide for digital terrestrial broadcasting [1]. Recently in 2016, the Malaysian government decided to broadcast free-to-air television latest technology by implementing DVBT2. A Signal is transmitted to all over the country by using 60 main transmitters and 40 gap fillers targeting about $98 \%$ of coverage in Malaysia until 2018. One of the transmitters is located at Menara Kuala Lumpur 
and this location will be used in this research. DVB-T2 is a second generation terrestrial broadcast transmission system, developed by the DVB project since 2006. Its main purpose is to increase capacity, ruggedness and flexibility to the then current DVB-T system [2]. As we indicated in our previous research [3], when considering the whole picture, it is evident that the latest technologies besides technical benefits, increased capacity for new services and higher quality of service, bring also a higher system cost.

The transition from Analog to DVB-T (first generation) and then continue the conversion from DVB-T to DVB-T2 are motivated by the process of merging those systems to be higher efficiency digital broadcast system which is DVB-T2. The meaning of high efficiency focuses on the capability of transmitting a large number of channels or high audio/video and coverage quality with the same amount of spectrum.DVB-T2 system also brings source coding improvement which is the double amount of channel on one MUX in High Definition (HD). The improvement of the system continues to offer larger coverage of Digital Terrestrial Television (DTT) with the same amount of transmitter characteristic, reception made, video quality and also number of channels [2], [12].

A lot of parameters can be related to the operation of DVB-T2 trough measurement. The first parameter is the distance to the transmitter (kilometer), whereby in this study, distance is measured from the transmitter's location at Menara Kuala Lumpur to the standpoint location, which is the location of the receiver. Second parameter is the field strength, measured using a field strength meter. Field strength represents the magnitude of electromagnetic vectors related to signal strength[3].The field strength is divided into two categories; Modulation Error Rate (MER) in unit $\mathrm{dB} \mu \mathrm{V} / \mathrm{m}$ representing the degree of constellation error which is used to measure the performance of transmitted and received signal, and Bit Error Rate after LDPC (BERaLDPC)in unit $\mathrm{dB} \mu \mathrm{V} / \mathrm{m}$. It is the channel's BER which is derived after LDPC Decoder DVB-T2.

DVB-T2 signals are highly influenced by the geology or terrain at the transmitter and receiver areas. Signal path can be obstructed by buildings or hills, especially in Kuala Lumpur, Malaysia area. This obstruction will cause signal reflection and diffraction and will be shown later on in the measurement and analysis sections of this paper. The same problem statement has occurred in the first generation of DVB, hence the placement of the receiving antenna must be considered, in order to compensate these issues to receive a better signal by placing, receiving antenna on a pole at a height of $10 \mathrm{~m}$ above ground and to measure the nearest accessible measurement point, preferably within a distance of $50 \mathrm{~m}$ around the ideal measurement point [4]. However, in the case of DVB-T2, the antenna study is extended to the use of indoor antenna. The other problem is a contradiction of signal strength and MER of receiving signal, whereby in some locations, strength of receiving signals is equal but MER of received signals are not equal. This condition happens due to the areas are obscured by the interference of environment [5]. To overcome this problem, it is suggested to use comparative analysis between MER and distance to indicate delay signal caused by the multipath effect of the reflection process. Then, by using measurement Bit Error Rate (BERbLDPC) - before LDPC, a minimum MER value that can be normally received by DVB-T2 can be determined [10], [11].

Since Malaysia will fully migrate to digital broadcasting by using the DVB-T2 system and analog transmission will be switched off entirely in 2018, this study will be helpful to provide information to government broadcasting station, Radio Television Malaysia (RTM) with regard to planning, implementing, commissioning and also testing the project. RTM also able to do further study in order to broad the area of study in measuring the performance of DVB-T2 since it is very new to broadcasters.

This project has high relevancy in broadcast technology in Malaysia because most of the study come from foreign country that has already implemented DVB-T2 as fully digital TV broadcasting which sometimes is not suitable for Malaysian environment and geographic area. Therefore, this is the right time to do the project. This study is also very helpful to the government to identify strengths and weaknesses of DVB-T2 audio and visual quality and this guideline can be useful to other broadcasters in order to implement it nationwide.

Delivering a robust signal, and offering a range of different modes and making it a very flexible standard, DVB-T2 can offer a much higher data rate and more robust signal than DVB-T [4][13]. Malaysia should adopt DVB-T2 as a standard for digital broadcasting in future. Therefore, this research was recommended to be expanding specifically in DVB-T2 which is the second generation of DVB. The suit parameter, method and analysis can be used and the analysis for the next study with new data collection and it also can include the comparison results between DVB-T and DVB-T2.

In addition, the main method that being used an appropriate simulation for some of the study carried are by using common simulation platform (CSP) and MATLAB [5]. To provide the performance evaluation of DVB-T2 for fixed reception by the received signal, measurement using field measurements was taken along 100 locations, for example, in Bangkok of Thailand [6]. It is suggested that same approach is used but 
change the venue to Malaysia especially in Kuala Lumpur since Malaysia is in progress to use fully digital in terrestrial TV in 2018. Some comparison are also being made in Thailand where the comparison is between the competency of the new Hata path loss model obtained from the optimization through least square method and the calibration on the statistical value of RMSE and ME in order to plan the broadcasting network design for DVB-T2 propagation in the urban Suratthani, southern Thailand.

According to Peter Corcoran and Stephen Dukes [2], all of the features of DVB-T2 make the system still relevant for several state of traditional broadcasting. Therefore, it is an advantage of DVB-T2 which can be embedded to various other existing signals. This makes DVB-T2 more flexible and integration with other system is possible. DVB-T2 has a lot of advantages in terms of parameter improvement and this study will prove it. In addition, the statement from Xian Lin Huang and Jun $\mathrm{Wu}$, Fei Hu, simulation results show KMV-Cast or typical linear video transmission called soft cast can reach a PSNR gain as Low SNR: 8db more, High SNR : 5db more and Traditional one : 7db more. They also focus on data compression than evaluate performance of the system under incomplete prior knowledge [7]. This means that the performance of DVB-T and DVB-T2 can be determined by test parameter and the quality of the audiovisual. If the performance of test parameter is good, then the quality of the visual at the receiver will be excellent. Furthermore, it is also stated that to identify the optimum value of C/M for correcting reception of DVB-T2 signal in condition after signal being fixed, the used optimum value of BER after LDPC decoding must be less or equal to $10^{-7}$ and BER after $\mathrm{BCH}$ decoding must be less or equal to $10^{-11}$ [8]. This condition is used in the study as a benchmark for a good quality signal.

The next parameter is the field strength and the MER, Teodor B. et al. [9] states that Field Strength, MER 30000 citizens minimum must be minimum $85 \mathrm{dbuV} / \mathrm{m}$ and others must be more than $56 \mathrm{dBuV} / \mathrm{m}$ than MER must be greater than 20-22dB. This guideline is suitable in order to have a baseline reading for field strength and MER. The comparison can be made, which compare the percentage of difference between test field strength and MER with the baseline value. The main objective of this research is to measure quality of Digital Video Broadcasting-Terrestrial Second Generation (DVB-T2) Signals in Kuala Lumpur Malaysia, which are field strength, MER and BERaLDPC, and then analyze and compare the results to DVB-T.

\section{METHODOLOGY}

DVB-T has several technical characteristics which can be varied to meet operator's requirement [10]. The characteristics are:

a) 4 choices of modulation QPSK (Quadrature Phase Shift Keying),16-QAM (16-Quadrature Amplitude Modulation), 64-QAM (64-Quadrature Amplitude Modulation) and 256-QAM (64-Quadrature Amplitude Modulation)

b) 6 different FEC (Forward Error Correction)

c) 7 Guard Interval option

d) $1 \mathrm{k}, 2 \mathrm{k}, 4 \mathrm{k}, 8 \mathrm{k}, 16 \mathrm{k}$ or $32 \mathrm{k}$ carriers

e) 6, 7 or $8 \mathrm{MHz}$ Channel bandwidths

A different combination of these parameters is chosen according to the need of network operators, such as, suitability between robustness and capacity. For example, although lower level of modulation such as QPSK has a slower data rate compared to 64-QAM, receivers can still receive the signal eventhough the signal is weak (robustness). Table 1 summarizes the difference in main parameters of DVB-T and DVB-T2 system.

Table 1. Parameter comparison between DVB-T and DVB-T2

\begin{tabular}{lll}
\hline Parameter & DVB-T & DVB-T2 \\
\hline Modulation & QPSK, 16QAM, & QPSK, 16QAM, 64QAM \\
& \& 64QAM & \& 256QAM \\
Forward Error & Convolutional & Low density parity-check \\
Correction & coding (CC) + & (LDPC) + Bose- \\
& Reed-Solomon & Chaudhuri-Hocquengham \\
& (RS) & (BCH) \\
Interval Option & $1 / 4,1 / 8,1 / 16, \&$ & $1 / 4,19 / 256,1 / 8,19 / 128$, \\
& $1 / 32$ & $1 / 16,1 / 32, \& 1 / 128$ \\
Discrete Fourier & $2 \mathrm{k} \& 8 \mathrm{k}$ & $1 \mathrm{k}, 2 \mathrm{k}, 4 \mathrm{k}, 8 \mathrm{k}, 16 \mathrm{k}, \&$ \\
Transform (DFT) & & $32 \mathrm{k}$ \\
Bandwidth & 6,7 and $8 \mathrm{Mhz}$ & $1.7,5.6,7,8$ and $10 \mathrm{Mhz}$ \\
\hline
\end{tabular}

Indonesian J Elec Eng \& Comp Sci, Vol. 13, No. 3, March 2019 : 1286 - 1293 
The methodology for this research can be divided into two parts; field test setup and data processing. At the beginning of this research, 100 test points are identified and selected from the RTM DVBT2 Coverage Simulation Database (Chirplus). Then DVB-T2 parameters; field strength, MER and BERaLDPC are measured and recorded. More details are given in Table 2.

\begin{tabular}{ll} 
Table 2. Basic parameters of DVB-T2 standard for this research \\
\hline System Parameter & DVB-T2 \\
\hline Forward error correction (FEC) \& & LDPC+BCH 2/3 \\
Code rates & \\
Modulation & 256-QAM \\
Rotation Constellation Mode & Non-Rotation mode \\
Guard Interval & $1 / 128$ \\
Subcarrier (FFT size) & $32 \mathrm{~K}$ \\
Bandwidth & $8 \mathrm{Mhz}$ \\
\hline
\end{tabular}

Figure 1 shows the flow diagram of this research which is the start of analysis on the DVB-T2 system. Next, 100 test points are chosen from the RTM DVB-T2 Coverage Simulation Database (Chirplus) to be the location of DVB-T2 receivers. Hence, this phase is the process of collecting required data, including field strength, MER, BERaLDPC and location information. Figure 2 and 3 demonstrate the block diagram of DVB-T and DVB-T2 receivers. There is a little difference between the two, especially in the measurement of BER. In DVB-T system, BER data are taken before and after Viterbi decoder. On the other hand, BER data in DVB-T2 system are taken before and after LDPC decoding. All parameters will be analyzed in order to determine the performance and the results will be compared with previous studies.

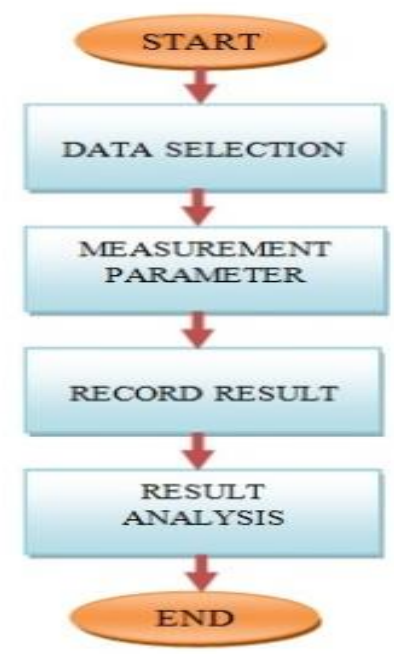

Figure 1. Flow diagram of research methodology

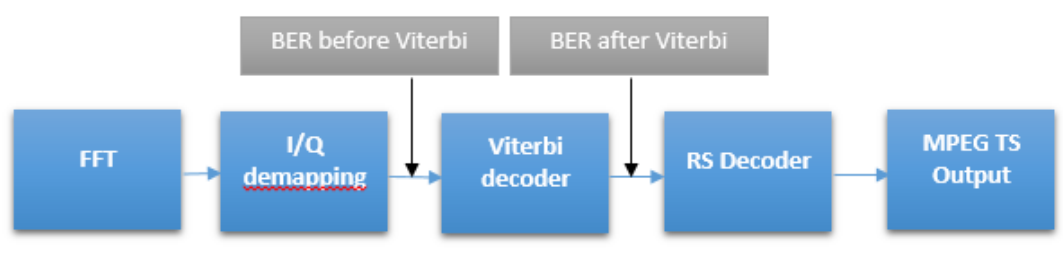

Figure 2. Simplified block diagram of a DVB-T receiver 


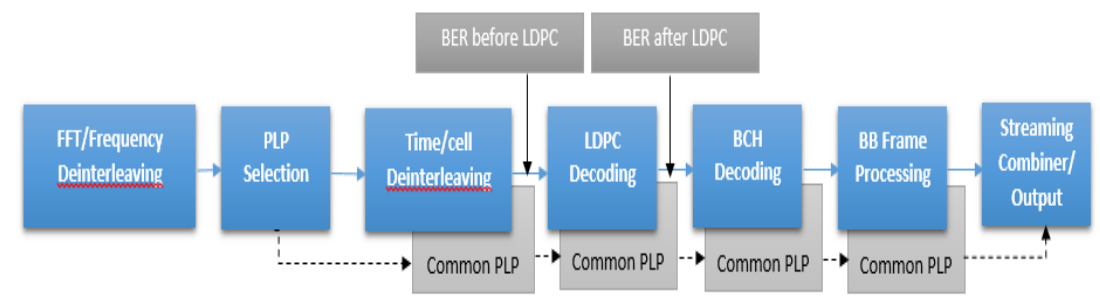

Figure 3. Simplified block diagram of a DVB-T2 receiver

The information needed from test point locations are latitude, longitude and distance to the transmitter. Measurement of field strength, BERaLDPC and MER at each test point are measured using test meter, Kathrein MSK130. Waveform monitor WVM 8210 is used to monitor the quality of the received signal/picture. Besides that, other equipments namely indoor antenna, distribution amplifier, DVB-T2 decoder and TV set are needed in order to get all the measurement. All mentioned data are collected during the measurement at the 100 test points and recorded in Microsoft Excel and then graphs are plotted and analyzed accordingly using MATLAB software. Figure 4 shows the field test setup diagram.

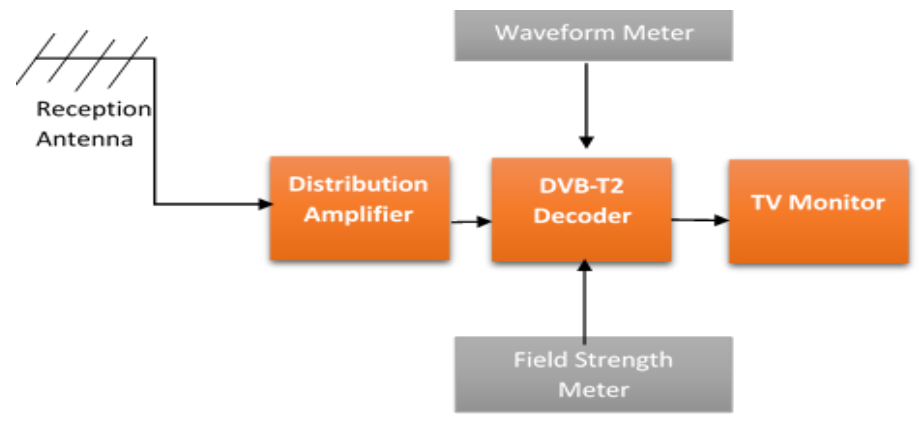

Figure 4. Field test setup block diagram

\section{RESULTS AND ANALYSIS}

The result parameters field strength, MER and BER are shown in Table 3. After collection data process is completed, results of the recorded parameters(field strength, MER and BER)against distance are presented in graphs using MATLAB software as shown in Figure 5, 6 and 7.

Figure 5 shows that $92 \%$ of field strength readings are above minimum level, which is $56(\mathrm{~dB} \mu \mathrm{V} / \mathrm{m})$ [9]. This result is considered good because the implementation of DVB-T2 in Malaysia is very new and most of the facility are still in research stage.

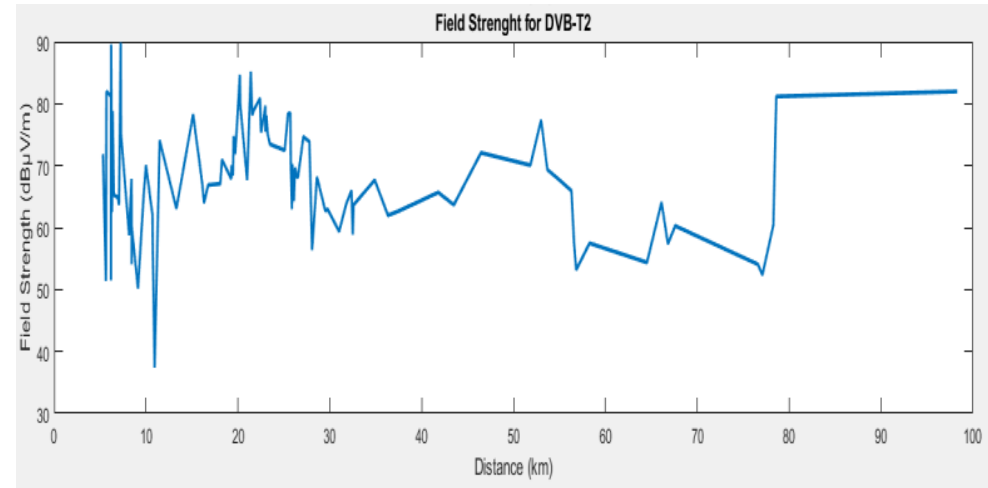

Figure 5. Field strength for DVB-T2 
Figure 6 demonstrates MER values at each test point against distance to the transmitter. Acceptable MER value is $20-22 \mathrm{~dB}$ [9] and $100 \%$ of the data tested is greater than this figure, hence it fulfills the requirement. This means that the quality of audio and visual is good enough at the 100 tested locations.

Value of BERaLDPC must be less than $10^{-7}$ [3] and all of collected data shows good result which is below the limit. The BER after LDPC versus distance to transmitter is shown in Figure 7. The result shows a weak dependence on the distance to the transmitter, which means that BER after LDPC values will be lower at longer distance compared to test point which is nearer to the transmitter. From the continuity of analysis, DVB-T2 results are compared with DVB-T and shown in Figures 8 and 9. Tested locations for both systems are same.

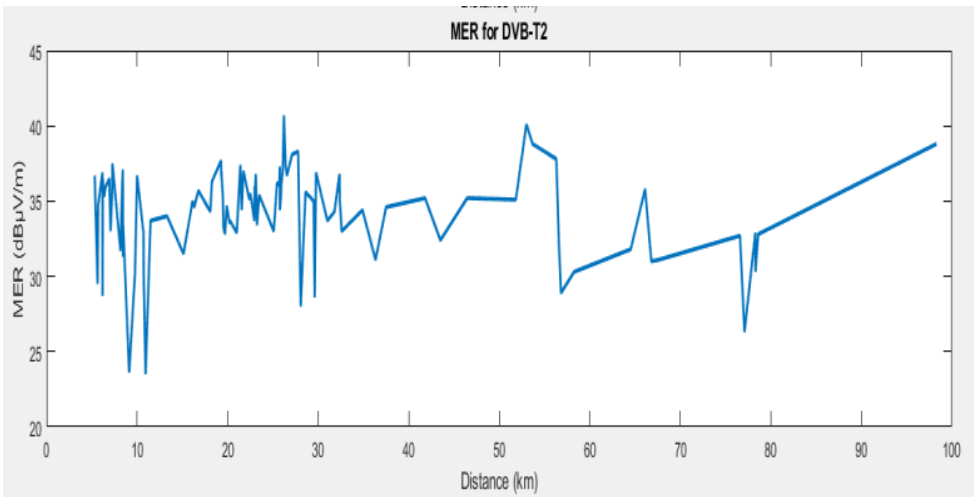

Figure 6. MER for DVB-T2

Table 3. Part of measurement results

\begin{tabular}{ccccc}
\hline TP & Km & FS $(\mathrm{dB} \mu \mathrm{V} / \mathrm{m})$ & MER $(\mathrm{dB})$ & BERaLDPC \\
\hline 1 & 5.31 & 71.875 & 36.7 & $0.00 \mathrm{E}+00$ \\
2 & 5.63 & 51.375 & 29.5 & $0.00 \mathrm{E}+00$ \\
3 & 5.69 & 81.975 & 34.7 & $0.00 \mathrm{E}+00$ \\
4 & 6.17 & 81.275 & 36.9 & $0.00 \mathrm{E}+00$ \\
5 & 6.18 & 51.475 & 28.7 & $0.00 \mathrm{E}+00$ \\
6 & 6.20 & 89.575 & 36.5 & $0.00 \mathrm{E}+00$ \\
7 & 6.29 & 62.475 & 35.9 & $0.00 \mathrm{E}+00$ \\
8 & 6.36 & 78.875 & 35.3 & $0.00 \mathrm{E}+00$ \\
9 & 6.49 & 65.275 & 35.9 & $3.78 \mathrm{E}-07$ \\
10 & 6.93 & 64.875 & 36.5 & $0.00 \mathrm{E}+00$ \\
11 & 7.06 & 63.675 & 33.0 & $0.00 \mathrm{E}+00$ \\
12 & 7.24 & 89.875 & 35.6 & $0.00 \mathrm{E}+00$ \\
13 & 7.27 & 75.175 & 37.5 & $0.00 \mathrm{E}+00$ \\
14 & 8.16 & 58.775 & 31.7 & $0.00 \mathrm{E}+00$ \\
15 & 8.36 & 66.175 & 36.2 & $0.00 \mathrm{E}+00$ \\
16 & 8.42 & 67.875 & 37.1 & $0.00 \mathrm{E}+00$ \\
17 & 8.43 & 54.075 & 31.3 & $0.00 \mathrm{E}+00$ \\
18 & 8.45 & 59.975 & 33.4 & $0.00 \mathrm{E}+00$ \\
19 & 9.12 & 50.175 & 23.6 & $0.00 \mathrm{E}+00$ \\
20 & 9.76 & 65.675 & 30.2 & $0.00 \mathrm{E}+00$ \\
\hline
\end{tabular}




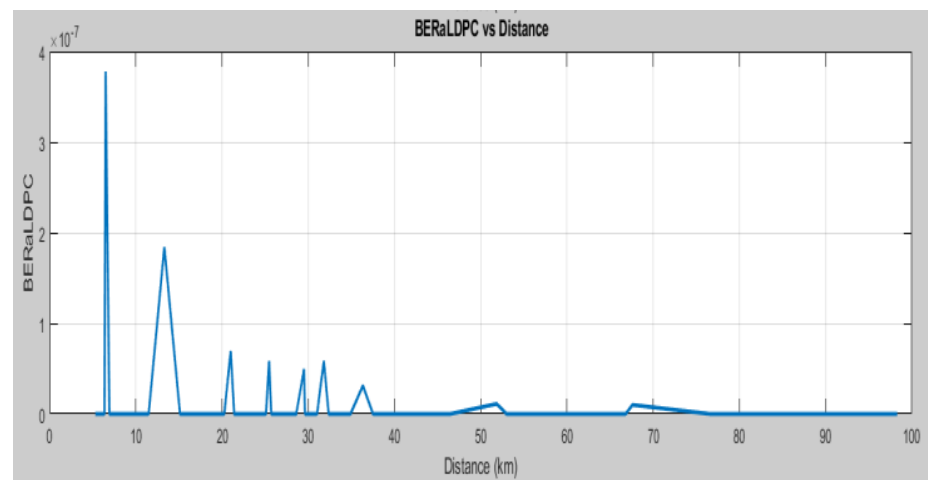

Figure 7. BERaLDPC for DVB-T2

Figure 8 indicates that there is an average of $1.5 \%$ increment in field strength of the second generation system (DBV-T2) compared to first generation (DVB-T), especially at locations further away than the transmitter. The increment is relatively small which could mean that field strength between the two systems are quite similar. However, it can also be said that DVB-T2 systems are better as signals in this system carry more channels and have a higher data rate of $30 \%$ [5]

Comparison of MER in Figure 9 demonstrates similar results as field strength. There is a constant improvement of about $3.8 \%$ in MER data of DVB-T2 systems at all test locations. While this value may seem to be low, the fact that signals in DVB-T2 system carry more channels and at the same time has higher MER values compared to DVB-T system, it may be deduced that DVB-T2 has better MER performance compared to DVB-T. Nevertheless, it could also mean that both systems have similar MER performance.

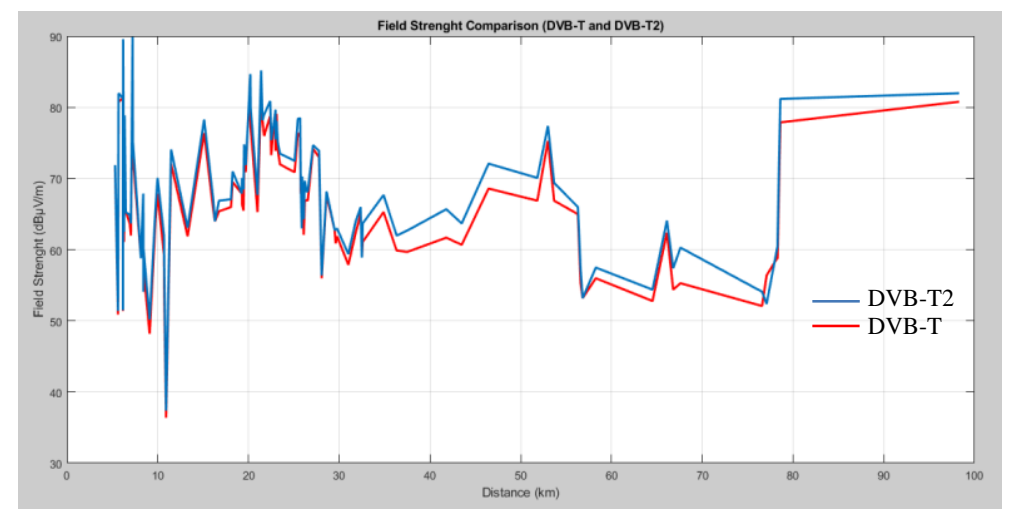

Figure 8. Field strength comparison graph between DVB-T and DVB-T2

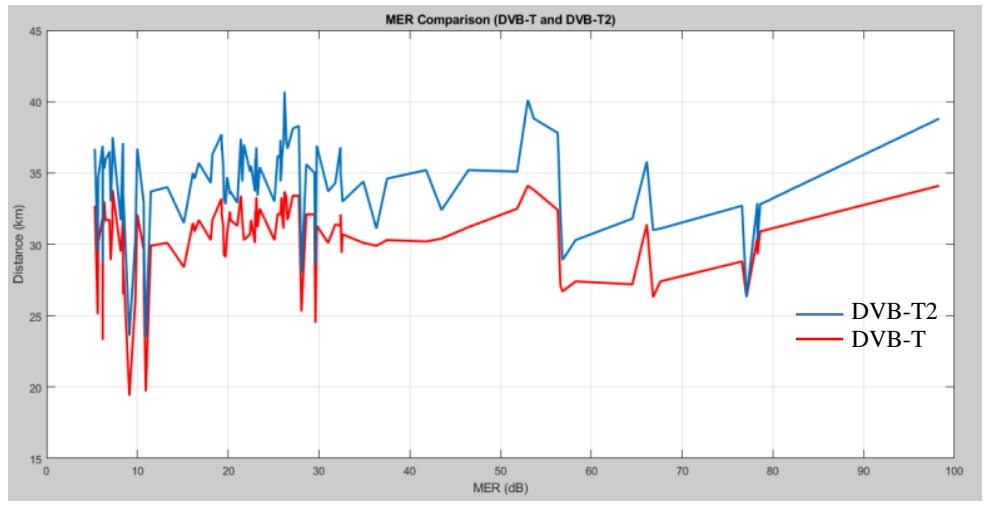

Figure 9. MER comparison graph between DVB-T and DVB-T2 


\section{CONCLUSION}

This research is expected to fill research gap in DVB-T2 studies, especially in Malaysia. Since Malaysia is on her way towards fully digital television transmission, this research can provide some information on performance and coverage of DVB-T2 signals. The objectives of the project are predicted to be fulfilled based on literature review and planned methods. The test which has been carried out demonstrated the performance of DVB-T in Malaysia (Klang Valley Area). DVB-T2 in Malaysia (Klang Valley area) has been successfully implemented and is currently being used for the transmission of 8 free-toair TV channels. Important parameters to determine the quality of a signal reception are field strength, MER and BER. Even though the measured parameters of the DVB-T2 system are higher than the DVB - T system, the differences are relatively very small and would not be prominent enough to suggest which system has better performance.For future studies, measurements of multi scale/ structural similarity index (MSSSIM/SSIM) and peak signal-to-noise ratio (PSNR) is suggested indicators to determine better and accurate performance in audio and visual of the digital TV.

\section{ACKNOWLEDGEMENTS}

The authors would like to thank Faculty of Electrical Engineering, Universiti Teknologi MARA (UiTM) for their valuable support.

\section{REFERENCES}

[1] W Fischer, Digital Video and Audio Broadcasting Technology, 3rd edn.Springer, Heidelberg, pp. 3- 4. pp. 765$767(2010$

[2] ITU-R Report, "ITU-R BT.2254-2 Frequency and network planning aspects of DVB-T2 BT Series Broadcasting service," vol. 2254, 2012.

[3] Sugaris, IReljin, Digital broadcasting techno-economic efficiency simulation model. Electron Electric Eng Mag.17 (3), 109-114 (2011)

[4] S. Wozniak, "Champions in Our Midst," IEEE Consumer Electronics Magazine, pp. 93-98, January 2016.

[5] Eizmendi, et al., "Empirical DVB-T2 thresholds for fixed reception," IEEE Trans. Broadcast., vol. 59, no. 2, pp. 306-316, 2013.

[6] Y. Norsuzila,et al., "Measurement of Digital Video Broadcasting- Terrestrial ( DVB-T ) Signal in Malaysia," $J$. Telecommun. Electron. Comput. Eng., vol. 9, no. 1-4, pp. 45-47, 2017.

[7] J. Abdullah et al., "Simulation of DVB B-T2 Integrated Receiver Decoder Specificatio ons for ASEAN Countrie es,"IEEE International Conference on Control System, Computing and Engineering, pp. 27-29, November 2015.

[8] B. Ruckveratham and S. Promwong, "Performance evaluation of DVB-T2 propagation for fixed reception," 2016 13th Int. Conf. Electr. Eng. Comput. Telecommun. Inf. Technol. ECTI-CON 2016, pp. 4-8, 2016.

[9] X.-L. Huang et al., "Knowledge-Enhanced Mobile Video Broadcasting (KMV-Cast) Framework with Cloud Support," IEEE Trans. Circuits Syst. Video Technol., vol. 8215, no. c, pp. 1-1, 2016.

[10] C. Regueiro et al., "Field Trials-Based Planning Parameters for DVB-T2 Indoor Reception," IEEE Trans. Broadcast., vol. 61, no. 2, pp. 251-262, 2015.

[11] T. B. Iliev et al., "Experimental Study of the Basic Parameters and the Field Strength of a Television Transmitter in the Single Frequency Network ( SFN )," 27th International Conference Radioelektronika, pp. 4-7, April 2017.

[12] Aleksandar Sugaris and Irini Reljin, "DVB-T2 technology improvements challenge current strategic planning of ubiquitous media networks", Journal on Wireless Communications and Networking 2012.

[13] S. Krishna Chaitanya Bulusu et al., "Quasi-Optimal Tone Reservation PAPR Reduction Algorithm for Next Generation Broadcasting Systems: A Performance/Complexity/Latency Tradeoff With Testbed Implementation”, SIEEE Transactions on Broadcasting , March 2018

[14] Berjon-Eriz G et al. , "Performance evaluation procedure for mobile DVB-T2 reception in urban environments", IEEE International Symposium on Broadband Multimedia Systems and Broadcasting, 2011

[15] Diego A. Samo et al., "A performance study of DVB-T2 and DVB-T2-Lite for mobile reception", Journal Digital Signal Processing, Volume 37 Issue C, February 2015, 